\title{
Psycholinguistic norms and face naming times for photographs of celebrities in French
}

\author{
Patrick Bonin, Cyril Perret, Alain Mtoot, Ludovic Ferrand, and Martial Mermillod \\ CNRS and Clermont Université, Clermont-Ferrand, Fnance
}

\begin{abstract}
A set of 105 photographs of celebrities has been standardized in French on distinctiveness, proper name agreement, face agreement, age of acquisition ( $\mathrm{AOA}$ ), and subjective frequency. Statistics on the collected variables for photographs are provided. The relationships between these variables have been analyzed. Face naming latencies have also been collected for the photographs of celebrities, and several multiple regression analyses have been carried out on naming latencies and percentages of tip-of-the-tongue (TOT) phenomena. The main determinants of naming speed included AoA, face agreement, and name agreement. In addition, AoA, together with distinctiveness and face agreement, reliably predicted the percentages of TOTs. The norms, photographs of the celebrities, and spoken naming latencies corresponding to the celebrities are available on the Internet at norms.celebrities.googlepages.com and should be of great use to researchers interested in the processing of famous people.
\end{abstract}

During the last 2 decades, psycholinguistic norms have been collected for a variety of stimuli: drawings of objects (e.g., Berman, Friedman, Hamberger, \& Snodgrass, 1989; Bonin, Peereman, Malardier, Méot, \& Chalard, 2003; Kremin, Hamerel, Dordain, De Wilde, \& Perrier, 2000; Martein, 1995; Snodgrass \& Vanderwart,1980), photographs and drawings of actions (Bonin, Boyer, Méot, Fayol, \& Droit, 2004; Cuetos \& Alija, 2003; Fiez \& Tranel, 1997; Masterson \& Druks, 1998; Schwitter, Boyer, Méot, Bonin, \& Laganaro, 2004; Szekely et al., 2005), and, more recently, celebrity names (Smith-Spark, Moore, Valentine, \& Sherman, 2006). Norms for objects have been collected for different languages and communities as well as for different populations. For instance, the most frequently used database-namely, the one developed by Snodgrass and Vanderwart, which contains 260 blackand-white drawings of objects-has been standardized in British English (Barry, Morrison, \& Ellis, 1997), French (Alario \& Ferrand, 1999), Spanish (Sanfeliu \& Fernandez, 1996), Icelandic (Pind, Jónsdóttir, Tryggvadóttir, \& Jónsson, 2000), and Chinese (Yoon et al., 2004). Norms have been made available to the research community for two main purposes. The first is that norms make it possible to control for a variety of potential variables that may affect performance when designing factorial experiments. For example, Alario and Ferrand's collection of French norms for the Snodgrass and Vanderwart drawings of objects has made it possible to design experiments that test the influence of both age of acquisition (AoA) and lexical frequency on picture naming latencies while controlling for many other relevant variables involved in picture naming, such as the visual complexity of the pictures, the codability of the pictures (name agreement), and the conceptual familiarity of the objects depicted by the pictures (e.g., Bonin, Fayol, \& Chalard, 2001). The second is that the availability of norms allows researchers to test precise hypotheses about the levels of processing that are involved in specific tasks (e.g., action naming, written or spoken naming). Likewise, numerous studies have used norms to investigate the determinants of naming speed (Barry et al., 1997; Bonin, Chalard, Méot, \& Fayol, 2002; Bonin et al., 2003; Chalard, Bonin, Méot, Boyer, \& Fayol, 2003; Cuetos, Ellis, \& Alvarez, 1999; Dell'Acqua, Lotto, \& Job, 2000; Snodgrass \& Yuditsky, 1996; see Alario et al., 2004, for a review). Moreover, the collection of psycholinguistic norms for photographs of actions in French has made it possible to test whether action naming and object naming involve the same kind of processes and representations and, if this is indeed the case, the extent to which the processes involved in action naming have the same weight as those involved in object naming (Bonin, Boyer, et al., 2004). Indeed, Bonin, Boyer, et al. found that action naming is more difficult than object naming and that the relative action naming difficulty is essentially attributable to the perceptual-conceptual level.

To our knowledge, psycholinguistic norms have not been collected for photographs of celebrities in French. To our knowledge, the only study that has collected norms for this kind of stimuli is the one conducted by Smith-Spark et al. (2006). We shall return to it later in this article. As is clear from the discussion above, it is important to collect norms for photographs of celebrities because this will help researchers to select stimuli on a variety of dimensions when they design experiments on face and/or proper 
name processing. Furthermore, the collection of norms for a large number of photographs of famous people permits the investigation of the processes and the representations underlying face processing. From a theoretical point of view, speech and written production models (e.g., Caramazza, 1997; Dell, 1986; Dell \& O'Seaghdha, 1992; Dell, Schwartz, Martin, Saffran, \& Gagnon, 1997; Levelt, Roelofs, \& Meyer, 1999) must be able to account for the production of any kind of item (verbs, adjectives, proper names) and not only object names. Indeed, the lexicalization process - that is, the process by which a concept to be expressed is transformed into an articulatory (or written) sequence and which is a central process in language production models (e.g., Caramazza, 1997; Levelt et al., 1999) - has thus far been framed essentially with reference to object naming. A central challenge is to determine whether proper names are given more processing specificity than common names and, if so, to what extent (Izaute \& Bonin, 2006). Certain studies have begun to explore this issue (Barry, Johnston, \& Scanlan, 1998; Izaute \& Bonin, 2001,2006 ). For instance, it has been suggested that semantic knowledge about people is organized around associative rather than categorical relationships (Barry et al., 1998; Izaute \& Bonin, 2006; but see Darling \& Valentine, 2005), whereas knowledge of objects appears to be organized both categorically and associatively (Alario, Segui, \& Ferrand, 2000).

It is well-known that the production of proper names is more difficult than the production of common names (Valentine, Brennen, \& Brédart, 1996). Indeed, proper names give rise to more tip-of-the-tongue (TOT) states than object names or abstract names (Burke, MacKay, Worthley, \& Wade, 1991). In addition, face naming takes longer than object naming in normal adults (Izaute \& Bonin, 2006), and the production of proper names is particularly vulnerable in cases in which word production is impaired due to brain damage (e.g., Brédart, Brennen, \& Valentine, 1997). Models of face naming have attempted to account for this type of processing difficulty. Certain models of face naming have been developed with reference to models of object naming (Izaute \& Bonin, 2001), whereas others have been developed on the basis of models of face processing (e.g., Bruce \& Young, 1986; Burton \& Bruce, 1992). In addition, recent studies in the field of neural network modeling have shown that general models of visual perception, simulating basic human perceptual and cognitive processes (Mermillod, Chauvin, \& Guyader, 2005; Mermillod, Guyader, \& Chauvin, 2005), can make it possible to unify object and face recognition within one and the same connectionist model (Dailey \& Cottrell, 1999). However, certain models of face naming clearly differ from certain models of object naming. For instance, people's names and identityspecific semantic information are represented at the same level in Burton and Bruce's face naming model, whereas in all models of object naming there is a clear-cut distinction between the semantic and the verbal levels (see Hillis, 2001 , for a review). A close examination of some models of face naming indicates that certain processing levels are common to both object and face naming but that there are also specific processing levels. Take, for example, the in- teractive activation and competition (IAC) model of face naming (Burton, Bruce, \& Johnston, 1990). In this model, face recognition units (FRUs) match perceptual input to stored representations of familiar faces. This level is similar to the structural level that is involved in object naming (Humphreys, Riddoch, \& Quinlan, 1988). From the FRU level, activation spreads to the personal identity node (PIN) level. It is assumed that each known person has a unique PIN that points to semantic information units. The latter level contains information about each individual's occupation, nationality, and so forth. The semantic level is also present in all object naming models. The perceptual and functional properties corresponding to objects are stored at this level. However, the PIN level is specific to models of face naming. These models also include a lexical level corresponding to the people's names. Based on object naming models, which assume a distinction between lemmas and lexemes, certain face naming models also make such a distinction (Brédart \& Valentine, 1992). It is also noteworthy that there are a number of empirical findings that are observed in both object naming and face naming (e.g., picture-name interference effects, repetition priming effects-Valentine \& Darling, 2006).

Because models of face and object naming share certain processing levels, the factors that are assumed to index specific processing levels in face and object naming should emerge as reliable determinants of naming speed in both tasks. We have already adopted this line of reasoning in exploring the issue of the levels that are shared by both written and spoken naming (Bonin et al., 2002) and by both action and object naming (Bonin, Boyer, et al., 2004). The same line of reasoning has also recently been applied by Roelofs (2004) to investigate in the levels shared by word reading and object naming. As reviewed by Alario et al. (2004), object naming studies have generally found that the main determinants of naming speed are name agreement, $\mathrm{AOA}$, and word frequency, although some discrepancies are found between these studies with regard to both the number of predictors included in the regression analyses and the question of which predictors are reliable. For instance, word frequency is reliable in six of the eight studies considered in Alario et al.'s (2004) review but not in the Italian study of Dell'Acqua et al. (2000) or in the French studies conducted by Bonin et al. (2002; Bonin et al., 2003) (but see Bonin, Barry, Méot, \& Chalard, 2004).

Object naming studies have identified two potential loci for name agreement (Vitkovitch \& Tyrrell, 1995). Name agreement is a measure of the degree of codability of an item-that is, how easy it is to assign a name to a given item. When the depicted objects are difficult to interpret (e.g., the picture of an ant may be confused with that of a spider), an effect of name agreement could arise as the result of incorrect responses that compete at the level of stored structural representations. In contrast, when the objects can be given alternative correct names (e.g., couch $\rightarrow$ sofa), the effect might be related to a competitive process involving correct responses, and the locus would therefore be lexical. However, with a few exceptions, celebrities have unique names, with the result that any effect of proper name 
agreement on face naming takes place at the level of FRUs only. Word frequency and AoA effects in object naming have generally been assumed to operate at the phonological level (Barry et al., 1997; Jescheniak \& Levelt, 1994; Levelt et al., 1999) or in the links between semantics and lexical representations (Bonin, Barry, et al., 2004; Ellis \& Lambon Ralph, 2000). Since face naming requires access to one specific name from semantic specifications corresponding to the individual in question, AOA and word frequency are clearly be expected to influence face naming speed (and accuracy). Both object and face naming require the perceptual analysis of the input (a face or an object) and its recognition. Because distinctiveness is assumed to index the level of FRUs, we anticipate that this variable should emerge as a reliable predictor of face naming speed. It is noteworthy, however, that in object naming studies the visual complexity of the objects that is thought to affect the object recognition level and, more precisely, the access to stored structural representations (Humphreys et al., 1988) has not been found to be a systematic determinant of object naming speed (Alario et al., 2004). In object naming, Barry et al. (1997) suggested that image agreement may have an impact at the level of stored structural representations: Objects whose pictures closely resemble the stored structural representations would be processed faster than objects whose pictures match the stored representations less well. In line with this account, faces whose photographs closely match the stored face representation at the level of the FRUs should be processed faster than faces whose photographs match the stored face representations less well.

In the present study, we collected five norms for $105 \mathrm{ce}$ lebrities: distinctiveness, proper name agreement, face agreement, $A 0 A$, and subjective frequency. Distinctiveness, AoA, and subjective frequency norms have also been collected by Smith-Spark et al. (2006). Our study differs from theirs in several respects. First, we collected norms from young adults only, whereas Smith-Spark et al. collected norms from adults over 40 years of age. Second, SmithSpark et al.'s norms were obtained on the basis of celebrity names, whereas we used celebrity names and/or celebrity photographs to obtain our norms. Third, Smith-Spark et al. did not report online measures obtained from their norms, whereas we recorded face naming times in response to the photographs of the celebrities. The details concerning the collection of the norms are provided below.

To summarize, the normative study reported here will be useful to researchers with a more general interest in face processing. The article is organized in two parts. The first part describes the collection of norms in French adults for 105 photographs of celebrities. The norms are available on the Internet at norms.celebrities.googlepages.com. Statistics corresponding to the collected variables are also reported. Correlational analyses have been performed on the variables collected for the photographs. The second part reports the collection of spoken naming times corresponding to the photographs of the celebrities (also available at the above-mentioned URL) as well as the correlation and multiple regression analyses. The face naming times will be very useful when it is time to select material for designing experiments.

\section{METHOD}

\section{Collection of the Norms}

Participants. A total of 223 psychology students from Clermont University participated in the normative study and were given course credit. Different participants were involved in each of the five rating tasks (44 participants in the distinctiveness task, 47 in the subjective frequency norming task, 44 in AoA ratings, 50 in the proper name agreement task, and 38 in the face agreement task). The participants (48 males and 175 females; mean age, 19 years; age range, 17-30 years) were all native speakers of French and had normal or corrected-to-normal vision. All the separate rating tasks were performed collectively.

Materials. The preliminary selection was performed with the participation of 101 psychology students (mean age, 20 years) who were not involved in any of the rating tasks. First, 17 students were provided with 30 professional and artistic categories. They had to write down the name of any celebrities they thought they could recognize on the basis of a photograph or a film. They were given $1 \mathrm{~min}$ per category to perform the task and were told to provide as many celebrities as they could think of. The 10 categories that yielded the greatest number of celebrities were chosen (actors, singers, athletes, TV stars, politicians, comics, scientists, novelists, painters, and historical figures). These 10 categories were then presented to 84 participants, who had to write down the maximum number of celebrities they thought they could recognize from a photograph or a film. The 105 most frequently cited celebrities were retained for the norming study. The photographs of the corresponding celebrities were taken from the Internet using a Google search. To be eligible, they had to be easily recognizable. The background of each photograph was erased using Adobe Photoshop (version F 1-40).

Procedure. The participants were tested collectively. At the beginning of each rating task, the instructions were both provided in writing on a separate sheet of paper and read aloud by the experimenter. The participants were instructed to perform their assigned rating task carefully and consistently. Individual answer sheets were prepared for each rating task. In each rating task, short breaks were given to the participants. In the proper name agreement and face agreement tasks, the pictures were projected on a large white screen by means of an overhead projector. For the AoA and subjective frequency ratings, the written proper name taken from the proper name agreement task was provided on the individual answer sheets. Sevenpoint scales were employed for all the tasks except the proper name agreement task and the face agreement task, for which 5-point scales were used. Great care was taken to explain to the participants that the full range of scale values had to be employed, and not only the extremes.

In the proper name agreement task, the participants were told to look carefully at each photograph and to write down the first name and surname of the celebrity on the answer sheet. Each time the participants failed to name a picture, they had to indicate whether it was because they did not recognize the person depicted by the photograph, did not know the name of the celebrity (in both of which cases they had to write down "unknown"), or were in a TOT state. A preliminary test on some pictures with different participants revealed that $5 \mathrm{sec}$ was enough to complete a written response. Each photograph was therefore presented for 5 sec.

In the face agreement task, the participants were asked to judge how closely each photograph resembled their mental representation of the celebrity. To this end, the modal name corresponding to the celebrity was presented for $2,000 \mathrm{msec}$, followed by an asterisk ( ${ }^{*}$ ) presented for $5,000 \mathrm{msec}$. During this period, the participant had to generate a mental image of the face of the celebrity. The photograph of the celebrity was then presented on the screen for $3,000 \mathrm{msec}$. Once the photograph was displayed, the participants had to rate on a 5-point scale the degree of agreement between the photograph and the image of the face they had generated for themselves, with 1 corresponding to low agreement and 5 corresponding to high agreement. 
The instructions used by Smith-Spark et al. (2006) for distinctiveness ratings were closed adhered to. The participants were asked to imagine how easy each celebrity would be to recognize from just his or her facial features. This was done on the basis of the image each participant had of the famous person in his or her mind's eye, rather than on the basis of a photograph. A 7-point scale was used, with 1 corresponding to a "typical," hard-to-spot face and 7 to a distinctive, easy-to-spot face. A distinctiveness effect has been observed in face recognition, and we know that distinctive faces are responded to more accurately and quickly than less distinctive or more typical ones (e.g., Sarno \& Alley, 1997; Valentine, 1991; Valentine \& Bruce, 1986).

For the AoA and subjective frequency tasks, the ratings were performed on the basis of the names of the celebrities that were taken from the individual answers from the proper name agreement task. A booklet containing all the modal verbs was prepared. A 7-point scale was printed below each celebrity name. In the AoA task, the participants had to estimate the age at which they thought they had learned each of the celebrity names. In this task, the values of the scale corresponded to 3-year age bands (on which $1=$ learned before 5 years old, 2 = learned between 6 and 8 years old, and $7=$ learned after 21 years old). AoA effects are robustly found in object and face naming (for reviews, see Johnston \& Barry, 2006, and Juhasz, 2005), with the result that items acquired early are named more quickly and accurately than items acquired late.

Because objective frequency counts are not available for celebrity names in French, we decided to collect subjective frequency values using a scale recommended by Forster (2000). A 7-point scale was used ( $1=$ never heard, read, or produced, $2=$ every year, $3=$ once per month, $4=$ once per week, $5=$ every 2 days, $6=$ once every day, $7=$ more than once every day). A positive relationship between rated familiarity of celebrity names and naming accuracy was reported by Brédart (1993).

\section{Collection of the Face Naming Times}

Participants. A total of 45 undergraduate students (41 females and 4 males; mean age, 19 years; range, 17-22 years) from Clermont University participated in the experiment in order to fulfill a course requirement and were given course credit. All were native speakers of French with normal or corrected-to-normal vision. None of them had participated in any of the rating tasks.

Materials. The stimuli consisted of the 105 photographs described above. Five additional items were used for training.

Apparatus. The experiment was run using PsyScope (Cohen, MacWhinney, Flatt, \& Provost, 1993) on a Power Macintosh. The computer controlled the presentation of the pictures and recorded the latencies. A Sony Vocal (F-V200) microphone connected to a button box was used to record the spoken latencies. The latencies were recorded to the nearest millisecond.

Procedure. The participants were tested individually. They sat in front of the screen at a distance of about $60 \mathrm{~cm}$. They were told that they would have to say aloud the first name and surname corresponding to each photographed celebrity presented on the screen as quickly as possible, and to avoid saying "um" or "er" before each name. Each time the participants failed to name a celebrity, they had to indicate whether it was because they did not recognize the person (by saying aloud "unknown") or because they did not know the name of the celebrity. However, when the participants felt they knew the name but were not able to retrieve it immediately, they had to say aloud "tip of the tongue." The experimenter monitored the participants' responses and scored them for correctness. (The experimenter recorded all naming errors, hesitations, and voice key failures.)

Each trial had the following structure: A ready signal ("*") appeared on the screen for $500 \mathrm{msec}$ and was immediately followed by the photograph. The next trial began $2,000 \mathrm{msec}$ after the participant had initiated his or her response. A short break was given to the participants after every 35 trials. The experiment started with five practice photographs. The order of presentation was randomized for each participant. The entire session lasted about $30 \mathrm{~min}$.

\section{RESULTS AND DISCUSSION}

\section{Rating Data}

The mean ratings collected for each photograph are available at norms.celebrities.googlepages.com. The items are listed alphabetically, and for each photograph the following information is provided: (1) the most common proper name obtained in the untimed proper name agreement task; (2) two measures of proper name agreement, corresponding to the percentage of participants giving the most common name and the $H$ statistic; and (3) the means and $S D$ s. The various proper names and their corresponding frequencies of occurrence are also provided for each of the photographs. The number of naming failures (e.g., TOT) is also given for each photograph. Finally, the mean spoken naming latency for each item is given in milliseconds. Numbers also indicate the order of naming speed for each celebrity (e.g., 1 for the celebrity with the shortest naming time, 2 for the celebrity with the second shortest naming time, and so on among the 105 celebrities).

\section{Descriptive Statistics}

Descriptive statistics corresponding to the different norms (proper name agreement, percentages of TOTs, AoA, distinctiveness, face agreement, subjective frequency, and number of phonemes included in the first name and surname) are presented in Table 1 . Name agreement was computed with and without the celebrity's first name. Following Snodgrass and Vanderwart (1980), two measures of (proper) name agreement were computed: the $H$ statistic and the percentages of participants producing the modal name (\%). The $H$ value equals 0 when the modal name was provided by all participants. Higher $H$ values indicate lower levels of name agreement. According to Snodgrass and Vanderwart, the $H$ measure is more sensitive to the heterogeneity of the names produced for an item than is percentage agreement.

The most noticeable findings were the following. Name agreement scores computed with the first name taken into account were very close to those computed with the family name only. The two measures exhibited pronounced asymmetries: negative for percentages and positive for the $H$ scores. $H$ scores were near zero in the majority of cases, indicating that very few alternative names were provided. Although the mean name agreement was generally high, celebrity names were provided by very few participants in certain cases. Distinctiveness scores exhibited a large negative asymmetry with a mean located at the top of the scale. Also, the scores exhibited a high variance in comparison with other norms using a 7-point scale. Thus, the great majority of faces were judged to be highly distinctive, whereas the remaining faces were judged to be highly similar. For AoA and face agreement, the participants mostly used the left part of the scale, with relatively low heterogeneities, thus indicating that the faces were generally not judged to be extremely different on these dimensions. However, a small negative asymmetry was observed for face agreement, suggesting that certain photographs did not match the mental representations of the celebrity faces formed by the participants. On the contrary, the mean 
Table 1

Summary Statistics in the Present Sample

\begin{tabular}{|c|c|c|c|c|c|c|c|c|c|c|c|}
\hline & $M$ & $S D$ & Median & Range & Min & Max & Q1 & Q3 & IQR & Skew I & Skew2 \\
\hline \multicolumn{12}{|l|}{ Name Agreement (\%) } \\
\hline$\%+$ FN & .72 & .23 & .80 & .91 & .09 & 1.00 & .55 & .91 & .36 & .44 & -.79 \\
\hline$\%-F N$ & .73 & .23 & .80 & .91 & .09 & 1.00 & .57 & .91 & .34 & .48 & -.81 \\
\hline$H+\mathrm{FN}$ & .23 & .35 & .15 & 1.88 & .00 & 1.88 & .00 & .29 & .29 & .93 & 2.07 \\
\hline$H-\mathrm{FN}$ & .20 & .34 & .00 & 1.88 & .00 & 1.88 & .00 & .24 & 24 & 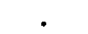 & 2.39 \\
\hline TOT & .17 & .13 & .15 & .72 & .00 & .72 & .07 & .28 & .21 & 1.63 & .98 \\
\hline Age of acquisition (1-7) & 3.89 & 0.66 & 3.89 & 2.90 & 2.43 & 5.33 & 3.31 & 4.41 & 1.10 & .90 & .06 \\
\hline Distinctiveness (1-7) & 5.41 & 1.00 & 5.82 & 4.09 & 2.66 & 6.75 & 4.72 & 6.16 & 1.44 & .31 & -.96 \\
\hline Face agreement $(1-5)$ & 3.65 & 0.64 & 3.76 & 3.21 & 1.53 & 4.74 & 3.13 & 4.16 & 1.03 & .63 & -.78 \\
\hline Subjective frequency $(1-7)$ & 2.98 & 0.75 & 2.89 & 3.68 & 1.43 & 5.11 & 2.44 & 3.35 & .91 & 1.02 & .75 \\
\hline Phons & 10 & 3 & 10 & 13 & 4 & 17 & 8 & 12 & 4 & 1.00 & .08 \\
\hline
\end{tabular}

Note-\%, percentage of participants giving the most common name; +FN, with the first name; $-F N$, without the first name; $H$, statistic $H$; TOT, percentages of tip-of-the-tongue experiences; Phons, number of phonemes for the first name plus the surname; Min, minimum; Max, maximum; Q1, 25th percentile; Q3, 75th percentile; IQR, interquartile range; Skew1, "(Q3 - median)/ (median $-Q 1)>1$ " is positively skewed; Skew2, "Fisher's $g_{1}$ coefficient of asymmetry $>0$ " is positively skewed.

and median subjective frequencies were situated below the center of the scale. With a variance that was relatively high in comparison to the mean, this variable exhibited a positive asymmetry, which suggests that some faces were perceived as much more frequently encountered than others. Finally, the number of TOTs was highly positively skewed, and a close examination of them revealed that they were extremely high for certain celebrities.

The mean proportion of participants giving the most common name was slightly lower for faces than for objects. For instance, it was .85 in Alario and Ferrand (1999) and .77 in Bonin et al. (2003) with very similar SDs. The skew was more negatively pronounced for faces, thus showing that agreement is lower for certain photographs. Since the number of alternitive names for people is generally smaller than the number of alternatives available for objects; which can sometimes be given alternative names (e.g., couch, sofa), the $H$ measure was lower for faces than for objects. The number of TOTs was higher for faces than for objects $(M=.022, \min =.0, \max =.4)$.

\section{Correlational Analyses}

The correlations obtained on the set of variables are shown in Table 2.

As can been seen in Table 2, there are two groups of positively correlated variables. In the first group, AoA, proper name agreement ( $H$ measure), and the number of TOTs are correlated; thus, celebrity names acquired early are associated with fewer alternative names and give rise to fewer TOTs than do names acquired late. In the second group, distinctiveness, face agreement, subjective frequency, and percent proper name agreement are correlated so that photographs to which high face agreement scores are assigned are related to faces that are judged to be more distinctive. Also, the more distinctive a face is judged to be, the more it is perceived as being frequently encountered and assigned a homogenous name. Except for the subjective frequency variable, which was not correlated with AoA, the variables of the first group were negatively correlated with those of the second.

The factors with noteworthy correlations with the number of phonemes are percent name agreement and number of TOTs, which suggests that celebrities having long given names and surnames cause more retrieval difficulties as assessed by both TOT states and name agreement scores. We also observed very high correlations between proper name agreement, distinctiveness, and face agreement. As a result, it should prove to be very difficult to control for these three variables when designing factorial experiments. Finally, the correlations between AoA and proper name agreement (and face agreement) were similar to those found in object naming studies. In contrast, the correlation between name agreement and image agreement was lower for objects in absolute terms than the correlation between proper name agreement and face agreement for celebrities.

Table 2

Correlations Among the Measured Variables

\begin{tabular}{lccccccc}
\hline & $\%+F N$ & $H+F N$ & TOT & AOA & Dis & FA & SF \\
\hline$H+$ FN & -.75 & & & & & & \\
TOT & -.82 & .44 & & & & & \\
AoA & -.49 & .29 & .55 & & & & \\
Dis & .85 & -.71 & -.67 & -.43 & & & \\
FA & .86 & -.70 & -.59 & -.33 & .82 & & \\
SF & .45 & -.44 & -.32 & .04 (n.s.) & .54 & .62 & \\
Phons & $-.23^{*}$ & .06 (n.s.) & $.24^{*}$ & .13 (n.s.) & -.14 (n.s.) & -.16 (n.s.) & .07 (n.s.) \\
\hline
\end{tabular}

Note- $\%$, percentage of participants giving the most common name; $+\mathrm{FN}$, with the first name; $H$, statistic $H$; TOT, percentages of tip-of-the-tongue experiences; AOA, age of acquisition; Dis, distinctiveness; FA, face agreement; SF, subjective frequency; Phons, number of phonemes for the first name plus the surname. "Significant at $p<.05$. All others (except those marked n.s.) are significant at $p<.01$. 
Table 3

Summary Statistics for Participants' Reaction Time Distributions (in Milliseconds) for Faces and Objects (Taken From Bonin et al, 2003)

\begin{tabular}{lccccccccccc}
\hline & $M$ & $S D$ & Median & Range & Min & Max & Q1 & Q3 & IQR & Skew1 & Skew2 \\
\hline Faces & 1,640 & 626 & 1,499 & 4,142 & 721 & 4,863 & 1,183 & 1,929 & 746 & 1.36 & 1.39 \\
Objects & 1,189 & 442 & 1,082 & 5,637 & 435 & 6,072 & 897 & 1,358 & 461 & 1.49 & 2.10 \\
\hline
\end{tabular}

Note-Min, minimum; Max, maximum; Q1, 25th percentile; $Q 3,75$ th percentile; IQR, interquartile range; Skew1, " $(\mathrm{Q} 3$ - median $) /$ (median $-\mathrm{Q} 1)>1$ " is positively skewed; Skew2, "Fisher's $g_{1}$ coefficient of asymmetry $>0$ " is positively skewed.

\section{Real-Time Naming Data}

The participants' naming times were very heterogeneous - that is, the number of naming attempts and the mean and $S D$ of the naming times varied considerably across naming times. In order to reduce this heterogeneity, 6 participants who differed greatly from the remaining participants on one or more of these dimensions were removed from further analyses. Four had a high rate of naming failures (they correctly named only about $10 \%-21 \%$ of the photographs), and 1 participant had a very long mean naming latency (about 3,900 msec). Finally, 1 participant had both a long mean naming latency and a long $S D$.

In order to permit a comparison with object naming latencies, the trimming procedure used in Bonin at al. (2003) was followed for the remaining scores: All latencies greater than two $S D$ s from each item's mean were eliminated. Applying this criterion lead us to discard 111 individual naming times. Thus, 2,160 naming times were retained for further analyses. 1

As is shown in Table 3, the naming latency distributions of objects (taken from Bonin et al., 2003) and those of faces are different: Naming times are generally faster and less heterogeneous for objects than for faces. However, the skew was higher for objects, an aspect that can be attributed partly to the fact that the number of items was higher for objects than for faces. These differences remained when items for which more than $50 \%$ of participants gave the most common name were taken into account (the maximum naming latencies were, however, reversed in this case).

Two multiple regression analyses were carried out with naming latencies as the dependent variable and percent proper name agreement, AoA, distinctiveness, face agreement, and subjective frequency included as independent variables. The number of phonemes was also included as a word length variable. Two multiple regression analyses were performed, one with the full set of items and the other with items having proper name agreement scores below $50 \%$ excluded. It is important to note that the large number of naming failures explains why the exclusion criterion for the faces used here is lower than that generally used for objects (i.e., in Bonin et al., 2003, the criterion for objects was "name agreement $<75 \%$ "). Because the correlations among proper name agreement, face agreement, and distinctiveness were high, these predictors exhibited considerable instability. Therefore, a stepwise approach was chosen. It is important to note, however, that the significant variables were the same regardless of whether the simultaneous multiple regression analysis used included face agreement only, distinctiveness only, or both these factors.

Proper name agreement and AoA were significant predictors in the two analyses, whereas face agreement and number of phonemes were significant only in the analysis from which items having proper name agreement below $50 \%$ were excluded (see Table 4).

As can be seen from Table 4, the analyses on naming times were also performed with proper name agreement excluded as an independent variable. This analysis was conducted in order to permit a direct comparison with the analyses reported below using the percentage of TOTs as the dependent variable. In this analysis, the same remaining independent variables were significant, except that face agreement was the first variable entered in the equation.

The same regression analyses were performed using the item percentages of TOTs as the dependent variable (see Table 5). However, proper name agreement was not included as a predictor because of its high correlation with the percentages of TOTs. The explanatory power of the equation for the occurrence of TOTs was similar to that found for naming times. One aspect worthy of note is that distinctiveness had the greatest predictive power in the

Table 4

Values of Multiple $\boldsymbol{R}$ and Beta Weights for the Independent Variables When Naming Times Are Used As the Dependent Variable

\begin{tabular}{rlrrrr}
\hline Multiple $R$ & Variable & $B$ & $S E$ & $t$ & $p$ \\
\hline \multirow{5}{*}{.691} & PNA & -.582 & .082 & -7.103 & $<.001$ \\
& AoA & .185 & .082 & 2.262 & .026 \\
& \multicolumn{6}{c}{ All Items } \\
.663 & All Items, PNA Not Included in the Equation & \\
& FA & -.498 & .079 & -6.332 & $<.001$ \\
& AoA & .303 & .079 & 3.855 & $<.001$ \\
& \multicolumn{7}{c}{ Items With PNA $\geq 50 \%$} & & \\
& PNA & -.376 & .119 & -3.154 & .002 \\
& Phons & .244 & .074 & 3.271 & .002 \\
& AoA & .210 & .084 & 2.513 & .014 \\
& FA & -.242 & .109 & -2.226 & .029
\end{tabular}

Items With PNA $\geq 50 \%$, PNA Not Included in the Equation

\begin{tabular}{llrrrr}
.716 & FA & -.490 & .079 & -6.203 & $<.001$ \\
& AoA & .326 & .079 & 4.119 & $<.001$ \\
& Phons & .266 & .078 & 3.402 & .001 \\
\hline
\end{tabular}

Note-Independent variables are listed in the order in which they were entered in the equation. PNA, proper name agreement (percentage of participants giving the most common proper name, including the first name); AoA, age of acquisition; FA, face agreement; Phons, number of phonemes for the first name plus the surname. 


\begin{tabular}{|c|c|c|c|c|c|}
\hline \multicolumn{6}{|c|}{$\begin{array}{l}\text { Table } 5 \\
\text { Values of Multiple } R \text { and Beta Weights for the } \\
\text { Independent Variables When Percentages of Tip-of-the-Tongue } \\
\text { Experiences Are Used As the Dependent Variable }\end{array}$} \\
\hline Multiple $R$ & Variable & $B$ & $S E$ & $t$ & $p$ \\
\hline \multicolumn{6}{|c|}{ All Items } \\
\hline .729 & $\begin{array}{l}\text { Dis } \\
\text { AoA }\end{array}$ & $\begin{array}{r}-.531 \\
.321\end{array}$ & $\begin{array}{l}.075 \\
.075\end{array}$ & $\begin{array}{r}-7.081 \\
4.282\end{array}$ & $\begin{array}{l}<.001 \\
<.001\end{array}$ \\
\hline \multicolumn{6}{|c|}{ Items With PNA $\geq 50 \%$} \\
\hline .736 & $\begin{array}{l}\text { Dis } \\
\text { AoA } \\
\text { FA }\end{array}$ & $\begin{array}{r}-.356 \\
.291 \\
-.299\end{array}$ & $\begin{array}{l}.105 \\
.080 \\
.100\end{array}$ & $\begin{array}{r}-3.392 \\
3.639 \\
-2.974\end{array}$ & $\begin{array}{r}.001 \\
<.001 \\
.004 \\
\end{array}$ \\
\hline
\end{tabular}

Note-Independent variables are listed in the order in which they were entered in the equation. PNA, proper name agreement (percentage of participants giving the most common proper name, including the first name); Dis, distinctiveness; AoA, age of acquisition; FA, face agreement.

two analyses, whereas this spot was taken by face agreement in the regression analyses on naming latencies. AoA again emerged as a reliable predictor of the percentages of TOTs.

In general, the results of the multiple regression analyses are consistent with those reported in the literature on object naming (e.g., Bonin et al., 2002; Chalard et al., 2003). As was found in the present study, object naming studies have shown that the two most reliable determinants of naming speed are name agreement and AoA (Barry et al., 1997; Bonin et al., 2002; Ellis \& Morrison, 1998; Gilhooly \& Gilhooly, 1979; Lachman, 1973; Lachman, Shaffer, \& Hennrikus, 1974; Paivio, Clark, Digdon, \& Bons, 1989; Snodgrass \& Yuditsky, 1996; Vitkovitch $\&$ Tyrrell, 1995). As setjout in the introduction, the locus of name agreement in object naming has generally been ascribed to the links between semantic and lexeme representations. When the links between these two kinds of representations are difficult to traverse, more time is needed to encode a verbal response.

The finding that AoA was reliable in the regression analyses with either naming times or percentages of TOTs is consistent with all the studies in which this variable has been used as an independent variable in order to predict performance in lexical processing tasks. The influence of AoA has been thought to arise at or around the level corresponding to the lexical representations of objects or actions (Barry et al., 1997; Bonin et al., 2002). There are several accounts of AoA effects in the literature, and it is not our intention to review them here (see Johnston \& Barry, 2006, and Juhasz, 2005, for reviews). However, it is important to note that recent studies have recommended that researchers interested in the influence of age-learning effects on lexical processing use frequency trajectories as an objective measure of age-limited learning effects instead of the classical (subjective or objective) AoA measures (Bonin, Barry, et al., 2004; Zevin \& Seidenberg, 2002, 2004). Frequency trajectory refers to age-related changes in word frequencies and has been found to be a reliable factor influencing the order of acquisition of words (Bonin, Barry, et al., 2004; Zevin \& Seidenberg, 2002). According to Zevin and Seidenberg (2002), because AoA measures are behavioral outcomes, they should not be used as inde- pendent variables to predict the speed and accuracy of lexical processing in adults. However, to date this advice has either not been followed in the literature or has not been clearly understood (Pérez, 2007). In the present study, we did not use frequency trajectory but the classic subjective AoA measures. Does this really matter? First of all, we did not possess the objective frequency norms for celebrity names in French that would be needed to compute frequency trajectory scores. Second, and more importantly, Bonin, Barry, et al. found that age-limited learning effects are found in tasks that involve arbitrary mappings (e.g., object naming, face naming) but not in tasks in which the links are more arbitrary when age-limited learning effects are assessed using frequency trajectory. Therefore, even though frequency trajectory norms should be preferred over AoA norms when available, the use of AoA norms to investigate tasks that clearly involve arbitrary mappings is not a significant issue. Age-limited learning effects are clearly expected in face naming, and, indeed, we found strong effects of AoA on both speed and accuracy (as assessed by TOTs) in our study.

We did not find that subjective frequency made a reliable contribution in predicting face naming times or the occurrence of TOTs. A number of studies conducted in the field of object naming have also failed to find a reliable contribution of lexical frequency when AoA norms are taken into account (e.g., Bonin et al., 2002; Bonin et al., 2001; Chalard et al., 2003). However, since AoA and subjective frequency were uncorrelated in the present study, the inclusion or omission of AoA in the regression model did not alter the reliability of subjective frequency. It should be stressed, however, that Bonin, Barry, et al. (2004) found that when more reliable measures of word frequency (i.e., cumulative frequency and not adult frequency) were taken into account together with the frequency trajectory, word frequency emerged as a reliable determinant of object naming speed. Cumulative frequency corresponds to how often words are encountered throughout a lifetime. Thus, adult frequency norms (as provided, for example, in English by the CELEX database-Baayen, Piepenbrock, \& van Rijn, 1993) do not provide reliable estimations of the cumulative frequency of words, since these may underrepresent the frequency of word exposure in childhood (Zevin \& Seidenberg, 2002). ${ }^{2}$ In the present study, since it was not possible to use cumulative (or adult) word frequency norms, it remains to be established whether the use of these measures of word frequency would be more successful in predicting face naming performance than the subjective word frequency norms. Since other face naming studies have reported a reliable effect of word frequency on naming times (Brédart, 1993), further research is needed to resolve the discrepancy.

Image agreement has not previously been included very frequently as a predictor of naming speed in object naming studies. However, when introduced in regression analyses, it proves to be a significant determinant of naming latencies, as found by Barry et al. (1997) and Bonin et al. (2002). In the present study, we used face agreement measures and again found this variable to be a reliable predictor of face naming speed (in the analyses restricted 
to items having a proper name agreement score $>50$ ) and of percentages of TOTs. In object naming, the influence of image agreement has been ascribed either to the level of structural representations when objects are especially difficult to recognize or to the level of lexical representation when objects have various alternative names. As explained in the introduction, as far as known faces are concerned, because celebrities usually have unique names, any influence of face agreement should be located at the level of the FRUs. Therefore, as has been found in object and action naming studies, face agreement is a reliable determinant of face naming and accuracy, and this variable should be taken into account when designing experiments that investigate face processing.

If we exclude the regression analyses on the percentages of TOTs, we note that distinctiveness did not make a reliable contribution to the prediction of face naming speed. However, in object naming studies, visual complexity, which is thought to index the recognition stage involved in object naming just as distinctiveness does in face naming, has not been found to contribute robustly to object naming times (Barry et al., 1997; Bonin et al., 2002; Cycowicz, Friedman, Rothstein, \& Snodgrass, 1997; Ellis \& Morrison, 1998; Jolicceur, 1985).

The number of phonemes was found to reliably predict face naming latencies in some of the regression analyses. As reviewed by Alario et al. (2004), in object naming studies the influence of length has not been found to systematically contribute to naming times. In effect, an examination of Alario et al.'s (2004) Table 4 reveals that, in object naming studies, word length is often not a reliable determinant of naming speed. Word length (as assessed by the number of phonemes) was a reliable determinant of face naming in our study, a result that may be attributable to the fact that proper names are generally longer than common names.

Our findings also confirm the well-known observation that proper names are more difficult to retrieve than common names. Burke et al. (1991) reported a higher rate of occurrence of TOTs on proper names than on common names. In the present study, we also found that the number of TOTs was considerably higher than in an earlier object naming study (Bonin et al., 2003). Also, the naming latency distributions of objects and faces were different, with naming latency being generally shorter and less heterogeneous for objects than for faces. Finally, the number of valid trials used in the multiple regression analyses was smaller than that generally used in object naming studies. The specific difficulty of accessing proper names has been ascribed to the existence of specific and unique links between PINs and lexical representations, unlike the case of objects, in which several semantic representations generally converge on lexical representations.

To conclude, the observation that the determinants identified as reliably influencing object naming performance are similar to those found in face naming strongly suggests that face naming involves levels of processing similar to those that have been identified in object naming. As Valentine and Darling (2006) claimed, speech proJustion models that can account for the empirical findings reveaied by face naming studies should be preferred over models developed to face naming alone. Our study represents a step in this direction, and we hope it will stimulate further research of this kind in the future.

\section{AUTHOR NOTE}

The authors thank Aurélie Saint-Jean and Caroline Bravard for their help in collecting the data, and Michael Cortese and an anonymous reviewer for helpful comments. M.M. wishes to thank the French National Research Agency (ANR Grant BLAN06-2_145908; ANR Grant ANR06-CORP-019). Correspondence concerning this article should be addressed to P. Bonin, Laboratoire de Psychologie Sociale et Cognitive, Université Blaise Pascal, 34, avenue Carnot, 63037 Clermont-Ferrand, France (e-mail: patrick.bonin@univ-bpclermont.fr).

\section{REFERENCES}

Alario, F.-X., \& Ferrand, L. (1999). A set of 400 pictures standardized for French: Norms for name agreement, image agreement, familiarity, visual complexity, image variability, and age of acquisition. Behavior Research Methods, Instruments, \& Computers, 31, 531-552.

alario, F.-X., Ferrand, L., Laganaro, M., New, B., Frauenfelder, U. H., \& SEGUI, J. (2004). Predictors of picture naming speed. Behavior Research Methods, Instruments, \& Computers, 36, 140-155.

AlarIo, F.-X., SEgul, J., \& FerRand, L. (2000). Semantic and associative priming in picture naming. Quarterly Journal of Experimental Psychology, 53A, 741-764.

BaAyen, R. H., Piepenbrock, R., \& van Run, H. (1993). The CELEX lexical database [CD-ROM]. Philadelphia: University of Pennsylvania, Linguistic Data Consortium.

Barry, C., Johnston, R. A., \& Scanlan, L. C. (1998). Are faces special "objects"? Associative and semantic priming of face and object recognition and naming. Quarterly Journal of Experimental Psychology, 51A, 853-882.

Barry, C., Morrison, C. M., \& Ellis, A. W. (1997). Naming the Snodgrass and Vanderwart pictures: Effects of age of acquisition, frequency, and name agreement. Quarterly Journal of Experimental Psychology, 50A, 560-585.

Berman, S., Friedman, D., Hamberger, M., \& Snodgrass, J. G. (1989). Developmental picture norms: Relationships between name agreement, familiarity, and visual complexity for child and adult ratings of two sets of line drawings. Behavior Reseanch Methods, Instruments, \& Computers, 21, 371-382.

Bonin, P., Barry, C., MEot, A., \& Chalard, M. (2004). The influence of age of acquisition in word reading and other tasks: A never ending story? Journal of Memory \& Language, 50, 456-476.

Bonin, P., Boyer, B., MÉt, A., FAYOL, M., \& Drolt, S. (2004). Psycholinguistic norms for action photographs in French and their relationships with spoken and written latencies. Behavior Research Methods, Instruments, \& Computers, 36, 127-139.

Bonin, P., Chalard, M., MÉt, A., \& Fayol, M. (2002). The determinants of spoken and written picture naming latencies. British Journal of Psychology, 93, 89-114.

Bonin, P., FAYOl, M., \& Chalard, M. (2001). Age of acquisition and word frequency in written picture naming. Quarterly Journal of Experimental Psychology, 54A, 469-489.

Bonin, P., Peereman, R., Malardier, N., Méot, A., \& Chalard, M. (2003). A new set of 299 pictures for psycholinguistic studies: French norms for name agreement, image agreement, conceptual familiarity, visual complexity, image variability, age of acquisition, and naming latencies. Behavior Research Methods, Instruments, \& Computers, 35, 158-167.

BrédART, S. (1993). Retrieval failures in face naming. Memory, 1, 351-366.

Brf́dart, S., Brennen, T., \& Valentine, T. (1997). Dissociations between the processing of proper and common names. Cognitive Neuropsychology, 14, 209-217.

Brédart, S., \& VAlentine, T. (1992). From Monroe to Moreau: An analysis of face naming errors. Cognition, 45, 187-223.

BRUCE, V., \& YouNG, A. (1986). Understanding face recognition. $P_{\text {rit:sen: }}$ Journal of Psychology, 77, 305-327.

BurKe, D., MACKAY, D. G., WorthleY, J. S., \& WADE, E. (1991). On 
the tip of the tongue: What causes word finding failures in young and older adults? Journal of Memory \& Language, 30, 542-579.

BURTON, A. M., \& BRUCE, V. (1992). I recognise your face but I can't remember your name. A simple explanation? British Journal of Psychology, 83, 45-60.

BURTON, A. M., BRUCE, V., \& Johnston, R. A. (1990). Understanding face recognition with an interactive activation model. British Journal of Psychology, 81, 361-380.

Caramazza, A. (1997). How many levels of processing are there in lexical access? Cognitive Neuropsychology, 14, 177-208.

Chalard, M., Bonin, P., MÉot, A., Boyer, B., \& Fayol, M. (2003). Objective age-of-acquisition (AOA) norms for a set of 230 object names in French: Relationships with other variables used in psycholinguistic experiments, the English data from Morrison et al. (1997), and naming latencies. European Journal of Cognitive Psychology, 15, 209-245.

Cohen, J., MacWhinney, B., Flatt, M., \& Provost, J. (1993). PsyScope: An interactive graphic system for designing and controlling experiments in the psychology laboratory using Macintosh computers. Behavior Research Methods, Instruments, \& Computers, 25, 257-271.

CUETOS, F., \& ALUA, M. (2003). Normative data and naming times for action pictures. Behavior Research Methods, Instruments, \& Computers, 35, 168-177.

Cuetos, F., Ellis, A. W., \& Alvarez, B. (1999). Naming times for the Snodgrass and Vanderwart pictures in Spanish. Behavior Research Methods, Instruments, \& Computers, 31, 650-658.

Cycowicz, Y. M., Friedman, D., Rothstein, M., \& Snodgrass, J. G. (1997). Picture naming by young children: Norms for name agreement, familiarity, and visual complexity. Journal of Experimental Child Psychology, 65, 171-237.

DaileY, M. N., \& CotTrell, G. W. (1999). Organization of face and object recognition in modular neural network models. Neural Networks, 12, 1053-1074.

DARIING, S., \& VAlENTINE, T. (2005). The categorical structure of semantic memory for famous people: $A$ new approach using release from proactive interference. Cognition, 96, 35-65.

DELL, G. S. (1986). A spreading-activation theory of retrieval in sentence production. Psychological Review, 93, 283-321.

Dell, G. S., \& O'SeaGHDHa, P. G. (1992). Stages of lexical access in language production. Cognition, 42, 287-314.

Dell, G. S, Schwartz, M. F., Martin, N., Saffran, E. M., \& GAGNON, D. A. (1997). Lexical access in aphasic and nonaphasic speakers. Psychological Review, 104, 801-838.

Dell'ACQUA, R., LotTo, L., \& JoB, R. (2000). Naming times and standardized norms for the Italian PD/DPSS set of 266 pictures: Direct comparisons with American, English, French, and Spanish published databases. Behavior Research Methods, Instruments, \& Computers, 32, 588-615.

Ellus, A. W., \& Lambon Ralph, M. A. (2000). Age of acquisition effects in adult lexical processing reflect loss of plasticity in maturing systems: Insights from connectionist networks. Journal of Experimental Psychology: Learning, Memory, \& Cognition, 26, 1103-1 123.

ElLIS, A. W., \& MoRRIson, C. M. (1998). Real age-of-acquisition effects in lexical retrieval. Journal of Experimental Psychology: Learning. Memory, \& Cognition, 24, 515-523.

FIEZ, J. A., \& Tranel, D. (1997). Standardized stimuli and procedures for investigating the retrieval of lexical and conceptual knowledge for actions. Memory \& Cognition, 25, 543-569.

FORSTER, K. I. (2000). The potential for experimenter bias effects in word recognition experiments. Memory \& Cognition, 28, 1109-11 15.

GiLHOOLY, K. J., \& GilHOOLY, M. L. M. (1979). Age-of-acquisition effects in lexical decision and episodic memory tasks. Memory \& Cognition, 7, 214-223.

Hnuls, A. E. (2001). The organization of the lexical system. In B. Rapp (Ed.), The handbook of cognitive neuropsychology: What deficits neveal about the human mind (pp. 185-210). Philadelphia: Psychology Press.

HumpHREYS, G. W., RidDOCH, M. J., \& QUinLaN, P. T. (1988). Cascade processes in picture identification. Cognitive Neuropsychology, $5,67-103$.

Izaute, M., \& BoniN, P. (2001). Proper name retrieval in written face naming: Exploration with the interference paradigm. Current Psychology Letters: Behaviour, Brain, \& Cognition, 6, 81-95.
IzaUTE, M., \& BonIN, P. (2006). Retrieval of names in face and object naming in an interference study. Memory, 14, 400-414.

JescheniaK, J. D., \& LevelT, W. J. M. (1994). Word frequency effects in speech production: Retrieval of syntactic information and of phonological form. Journal of Experimental Psychology: Learning, Memory, \& Cognition, 20, 824-843.

JoHnston, R. A., \& BARRY, C. (2006). Age of acquisition and lexical processing. Visual Cognition, 13, 789-845.

JOLICEUR, P. (1985). The time to name disoriented natural objects. Memory \& Cognition, 13, 289-303.

JuHASZ, B. (2005). Age-of-acquisition effects in word and picture identification. Psychological Bulletin, 131, 684-712.

Kremin, H., Hamerel, M., Dordain, M., De Wilde, M., \& Perrier, D. (2000). Age of acquisition and name agreement as predictors of mean response latencies in picture naming of French adults. Brain \& Cognition, 43, 286-291.

LACHMAN, R. (1973). Uncertainty effects on time to access the internal lexicon. Journal of Experimental Psychology, 99, 199-208.

LaChman, R., ShaFFER, J. P., \& HennRIKus, D. (1974). Language and cognition: Effects of stimulus codability, name-word frequency, and age of acquisition on lexical reaction time. Journal of Verbal Learning \& Verbal Behavior, 13, 613-625.

LEVELT, W. J. M., ROELOFS, A., \& MEYER, A. S. (1999). A theory of lexical access in speech production. Behavioral \& Brain Sciences, 22, 1-75.

MARTEIN, R. (1995). Norms for name and concept agreement, familiarity, visual complexity and image agreement on a set of 216 pictures. Psychologica Belgica, 35, 205-225.

Masterson, J., \& DruKs, J. (1998). Description of a set of 164 nouns and 102 verbs matched for printed word frequency, familiarity and age-of-acquisition. Journal of Neurolinguistics, 11, 331-354.

Mermillod, M., Chauvin, A., \& GuYader, N. (2005). Improving generalisation skills in a neural network on the basis of neurophysiological data. Brain \& Cognition, 58, 246-248.

Mermilod, M., GuYader, N., \& Chauvin, A. (2005). The coarse-tofine hypothesis revisited: Evidence from neuro-computational modeling. Brain \& Cognition, 57, 151-157.

Paivio, A., ClakK, J. M., Digdon, N., \& Bons, T. (1989). Referential processing: Reciprocity and correlates of naming and imaging. Memory \& Cognition, 17, 163-174.

PErez, M. A. (2007). Age of acquisition persists as the main factor in picture naming when cumulative word frequency and frequency trajectory are controlled. Quarterly Journal of Experimental Psychology, $60,32-42$.

Pind, J., Jónsdóttir, H., TryggvadótTiR, H. B., \& Jónsson, F. (2000). Icelandic norms for the Snodgrass and Vanderwart (1980) pictures: Name and image agreement, familiarity, and age of acquisition. Scandinavian Journal of Psychology, 41, 41-48.

RoElors, A. (2004). Seriality of phonological encoding in naming objects and reading their names. Memory \& Cognition, 32, 212-222.

Sanfeliu, M. C., \& Fernandez, A. (1996). A set of 254 SnodgrassVanderwart pictures standardized for Spanish: Norms for name agreement, image agreement, familiarity, and visual complexity. Behavior Research Methods, Instruments, \& Computers, 28, 537-555.

SARNo, J. A., \& AlLEY, T. R. (1997). Attractiveness and the memorability of faces: Only a matter of distinctiveness? American Journal of Psychology, 110, 81-92.

SChWTTter, V., Boyer, B., MÉot, A., Bonin, P., \& Laganaro, M. (2004). French normative data and naming times for action pictures. Behavior Research Methods, Instruments, \& Computers, 36, 564-576.

Smith-Spark, J. H., Moore, V., Valentine, T., \& Sherman, S. M. (2006). Stimulus generation, ratings, phoneme counts, and group classifications for 696 famous people by British adults over 40 years of age. Behavior Research Methods, 38, 590-597.

SNODGRASS, J. G., \& VANDERWART, M. (1980). A standardized set of 260 pictures: Norms for names agreement, image agreement, familiarity, and visual complexity. Journal of Experimental Psychology: Human Learning \& Memory, 6, 174-215.

SNodgrass, J. G., \& Yuditsky, T. (1996). Naming times for the Snodgrass and Vanderwart pictures. Behavior Research Methods, Instruments, \& Computers, 28, 516-536.

SzeKely, A., D'Amico, S., Devescovi, A., Federmeier, K., Herron, D., IYER, G., ET AL. (2005). Timed action and object naming. Cortex, 41, 7-26. 
VALENTINE, T. (1991). A unified account of the effects of distinctiveness, inversion, and race in face recognition. Quarterly Journal of Experimental Psychology, 43A, 161-204.

VALENTINE, T., BRENNEN, T., \& BréDART, S. (1996). The cognitive psychology of pnoper names: On the importance of being Ernest. London: Routledge.

VALENTINE, T., \& BRUCE, V. (1986). The effects of distinctiveness in recognising and classifying objects and faces. Perception, 15, 525-535.

VAlentine, T., \& DARLiNG, S. (2006). Competitor effects in naming objects and famous faces. European Journal of Cognitive Psychology, 18, 686-707.

VITKOVITCH, M., \& TYRRELL, L. (1995). Sources of disagreement in object naming. Quarterty Journal of Experimental Psychology, 48A, 822-848.

Yoon, C., Feinberg, F., Luo, T., Hedden, T., Gutchess, A. H., Chen, H.-Y. M., ET AL. (2004). A cross-culturally standardized set of pictures for younger and older adults: American and Chinese norms for name agreement, concept agreement, and familiarity. Behavior Research Methods, Instruments, \& Computers, 36, 639-649.

Zeno, S. M., IVEns, S. H., Millard, R. T., \& DuvvuRi, R. (1995). The educator's word frequency guide. Brewster, NY: Touchstone Applied Science Associates.
ZeVIn, J. D., \& SEIDENBerg, M. S. (2002). Age of acquisition effects in word reading and other tasks. Journal of Memory \& Language, 47, 1-29.

ZeVIN, J. D., \& SEIDENBERG, M. S. (2004). Age-of-acquisition effects in reading aloud: Tests of cumulative frequency and frequency trajectory. Memory \& Cognition, 32, 31-38.

\section{NOTES}

1. Stated differently, the remaining naming data corresponds to $49 \%$ of the 4,410 theoretical items. In comparison with the object naming times collected by Bonin et al. (2003), this percentage is relatively small, since it was $69 \%$ when the same trimming procedure was applied to the naming data.

2. For American English, cumulative frequency estimates can be computed using Zeno's (1995) word frequency guide. This corpus provides estimates of how often words are encountered at multiple points during a subject's lifetime, from initial acquisition (in first grade) to adulthood.

(Manuscript received April 25, 2007; revision accepted for publication July 25,2007 .) 